\title{
Pelatihan Pembelajaran Kewarganegaraan Untuk Guru Sekolah Dasar Berbasis Multimedia Dan Augmented Reality
}

\author{
Yessy Asri $^{1}$; Muhamad Jafar Elly ${ }^{2}$; Dwina Kuswardani ${ }^{3}$ \\ ${ }^{1,2,3}$ S1 Teknik Informatika, Fakultas Telematika Energi, Institut Teknologi PLN \\ 1'yesfar2@gmail.com \\ 2 jafar_elly08@yahoo.com \\ ${ }^{3}$ dwina2562@gmail.com
}

\begin{abstract}
Community Service aims to develop the application of Archipelago Insight in an effort to improve national awareness, national values in empowerment, and strengthening national and state awareness based on Pancasila, the 1945 Constitution, Unity in Diversity and the Unitary Republic of Indonesia for primary school teachers with multimedia technology. and augmented reality. Problems arise about how to apply an appropriate learning method to provide knowledge and understanding of citizenship to students, especially in the midst of Pandemic Covid 19 right now, which does not seem easy to provide knowledge and understanding of citizenship to elementary students using conventional methods as before the pandemic. This Citizenship Learning Method Training for Elementary School Teachers tries to offer learning method solutions to students who are mostly primary school teachers from various regions of Indonesia. This training activity was conducted online using the zoom meeting application that successfully attracted participants from various regions of the country, including Jakarta, Depok, Tangerang, Bekasi, Central Sulawesi, and East Java. Approximately fifty participants attended this training. This technology has previously been applied in several primary schools in Bekasi. The result is an increase in students' knowledge and understanding when using the technological approach. The citizenship learning application system describes the material content that covers three main things that are interconnected in the learning process, namely learning, play and training. These three things are presented in an easy and attractive way through a combination of text, images, sound, animation and video. It is hoped that this method can attract the interest of elementary students to learn and understand about Indonesian nationality and knowledge.
\end{abstract}

Keywords: Learning Media, Citizenship, Teachers, Multimedia, Augmented Reality

\begin{abstract}
ABSTRAK
Pengabdian Pada Masyarakat ini bertujuan untuk membangun aplikasi Wawasan Nusantara dalam upaya meningkatkan wawasan kebangsaan, nilai-nilai kebangsaan dalam pemberdayaan dan penguatan kesadaran berbangsa dan bernegara yang berlandaskan pada Pancasila, UUD 1945, Bhinneka Tunggal Ika, dan NKRI bagi Guru Sekolah Dasar dengan teknologi berbasis Multimedia dan Augmented Reality. Permasalahan muncul bagaimana menerapkan suatu metode pembelajaran yang tepat untuk memberikan pengetahuan dan pemahaman tentang kewarganegaraan itu ke peserta didik, apalagi di tengah Pandemic Covid 19 saat ini yang rasanya tidak mudah memberikan pengetahuan dan pemahaman kewarnegaraan itu kepada para siswa SD menggunakan cara-cara konvensional seperti masa sebelum pandemik. Pelatihan Metode Pembelajaran Keewarganegaraan untuk Guru Sekolah Dasar ini mencoba menawarkan solusi metode pembelajaran kepada peserta pelatihan yang sebagian besar adalah guru sekolah dasar dari berbagai wilayah di Indonesia.
\end{abstract}


Kegiatan pelatihan ini dilaksanakan secara online menggunakan aplikasi zoom meeting yang sukses menarik peserta dari berbagai wilayah di tanah air, di antaranya dari Jakarta, Depok, Tangerang, Bekasi, Sulawesi Tengah, dan Jawa Timur. Lebih kurang lima puluh peserta hadir dalam pelatihan ini. Teknologi ini sebelumnya sudah diterapkan di beberapa sekolah dasar di Bekasi. Hasilnya ada peningkatan pengetahuan dan pemahaman peserta didik ketika menggunakan pendekatan teknologi tersebut. Sistem aplikasi pembelajaran kewarganegaraan ini secara garis besar muatan materinya mencakup tiga hal utama yang saling berhubungan dalam proses pembelajaran, yakni belajar, bermain dan latihan. Ketiga hal tersebut disajikan dengan mudah dan menarik dengan kombinasi teks, gambar, suara, animasi dan video. Cara ini diharapkan dapat menarik minat para siswa SD untuk belajar dan memahami tentang kewarganegaraan dan wawasan kebangsaan Indonesia.

Kata kunci: Media Pembelajaran, Kewarganegaraan, Guru, Multimedia, Augmented Reality 


\section{PENDAHULUAN}

Pendidikan Wawasan Nusantara didefinisikan sebagai sudut pandang atau cara memandang yang mengandung kemampuan seseorang atau kelompok orang untuk memahami keberadaan jati dirinya sebagai suatu bangsa, juga dalam memandang dirinya dan tingkah laku sesuai falsafah hidup bangsanya dalam lingkungan internal dan lingkungan eksternalnya [3][7]. Dalam kehidupan berbangsa dan bernegara terdapat kesepakatan yang disebut sebagai empat pilar kehidupan berbangsa dan bernegara. Empat pilar ini adalah Pancasila, UUD 1945, NKRI dan Bhineka Tunggal Ika. Pilar adalah tiang penyangga suatu bangunan agar bisa berdiri secara kokoh. Bila tiang ini rapuh maka bangunan akan mudah roboh [15]. Faktor-faktor yang mempengaruhi Wawasan Nusantara yaitu (1) Wilayah (2) Geopolitik dan Geostrategi (3) Perkembangan wilayah Indonesia dan dasar hukumnya. Lima hal yang terkandung dalam makna Wawasan Nusantara, diantaranya: 1) Pro Patria dan Primus Patrialis, mencintai tanah air dan mendahulukan kepentingan tanah air. 2) Jiwa solidaritas dan kesetiakawanan dari semua lapisan masyarakat terhadap perjuangan kemerdekaan. 3) Jiwa toleransi atau tenggang rasa antaragama, antarsuku, antargolongan, dan antarbangsa. 4) Jiwa tanpa pamrih dan bertanggung jawab. 5) Jiwa ksatria dan kebesaran jiwa yang tidak mengandung balas dendam [16].

Memperhatikan semakin menipisnya Wawasan Nusantara saat ini, rapuhnya nilai-nilai Wawasan Nusantara di tengah-tengah masyarakat, khususnya generasi muda, tidak lepas dari pengaruh perkembangan arus globalisasi. Derasnya perkembangan informasi dan teknologi, memberikan pengaruh terhadap cara dan pola pandang generasi muda terhadap nilai-nilai kebangsaan. Arus gloalisasi, salah satu faktor yang menyebabkan lunturnya nilai-nilai Wawasan Nusantara, letak geografis suatu daerah, yang berada di pintu gerbang dan sekaligus kawasan terluar negara kesatuan Republik Indonesia, sangat mudah menerima informasi-informasi dari negeri tetangga [8][9][19][10][11][13][14]. Oleh karena itu, sebagai masyarakat yang berada di beranda utama dan tiang penyangga sebuah bangsa, hendaknya harus selalu memperkokoh nilai-nilai Wawasan Nusantara. Tidak hanya itu, lunturnya nilai-nilai Wawasan Nusantara juga disebabkan oleh pengaruh konflik di masyarakat dan masuknya paham aliran sesat di tengah-tengah masyarakat. Berikut beberapa hasil riset dan survey terkait dengan rapuhnya Wawasan Nusantara pada generasi muda: 1) bersumber dari http://www.halloriau.com/read-bengkalis-69657-2015-08-28-akibat-arusglobalisasi-nilai-wawasan-kebangsaan-rapuh.html, dengan hasil surveynya "Akibat Arus Globalisasi, Nilai Wawasan Nusantara Rapuh, derasnya pengaruh teknologi dan informasi memberikan pengaruh terhadap cara dan pola pandang generasi muda terhadap nilai-nilai kebangsaan". 2) http://www.pikiran rakyat.com/pendidikan/2012/04/22/185563/wawasankebangsaan-luntur-timbulkan perpecahan, dengan hasil surveynya : "Wawasan Nusantara Luntur, Timbulkan Perpecahan, banyak hal yang menyebabkan lunturnya sikap patriotik itu, di antaranya ialah pemahaman Wawasan Nusantara generasi muda, patriotisme yang masih identik dengan pemerintahan membuat tingkat kepercayaan masyarakat pada penumbuhan sikap patriotik semakin menurun". 3) Lembaga Kajian Demokrasi dan Hak Asasi (Demos) dan Pamflet dan Hivos Indonesia, dengan hasil riset sebanyak $68 \%$ anak muda kehilangan pegangan dan kesulitan membedakan mana yang benar dan mana yang salah sehingga mereka mencari nilai-nilai baru diluar jati diri bangsa, saat itulah paham-paham luar tersebut semakin mudah menggerogoti tunas bangsa dan membuat mereka tidak mengenal benteng ideology pemersatu bangsa Indonesia, Pancasila. 


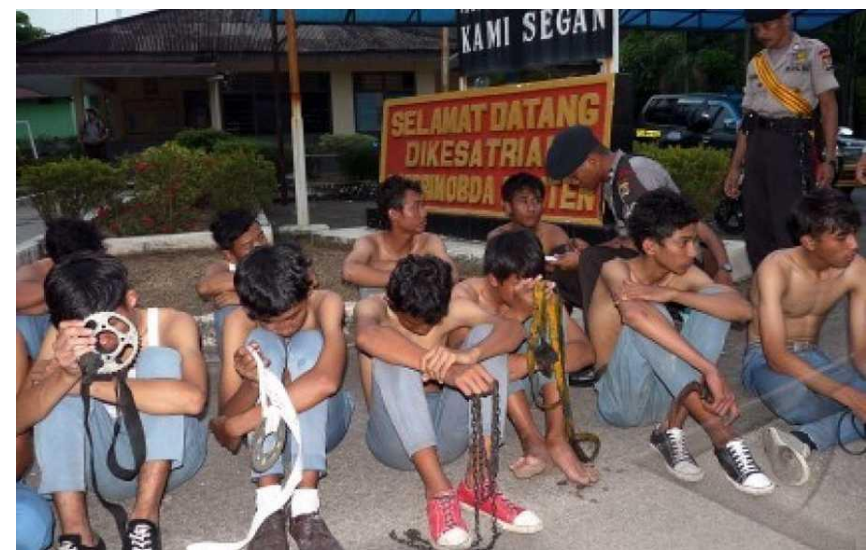

Gambar 1. Penganiayaan Siswa Sekolah Bekasi

Di Indonesia, pendidikan Wawasan Nusantara telah menjadi salah satu kurikulum pada Sekolah Dasar (SD). Pendidikan Wawasan Nusantara terdapat pada mata pelajaran Kewarganegaraa yang dimulai dari kelas 2 hingga kelas 6 [12]. Pendidikan Wawasan Nusantara yang diberikan di sekolah bukan hanya sekedar untuk mendapatkan nilai tetapi pengajaran Wawasan Nusantara secara formal tersebut mempunyai arti yang luas dan mendalam. Dalam kehidupan masyarakat Wawasan Nusantara mempunyai arti dan peran penting sebab dengan belajar Wawasan Nusantara Republik Indonesia akan menjadikan peningkatan karakter bangsa dalam pelaksanaan nilai-nilai Wawasan Nusantara dalam pemberdayaan dan penguatan kesadaran berbangsa dan bernegara yang berlandaskan pada Pancasila, UUD 1945, Bhinneka Tunggal Ika, dan NKRI.

Melalui usulan Pengabdian Pada Masyarakat ini, tim kami mencoba membangun sebuah aplikasi berbasis Augmented Reality dalam upaya peningkatan Wawasan Nusantara bagi generasi muda bangsa. Hal itu dimungkinkan dengan menerapkan berbagai teknik teknologi Multimedia dan Augmented Reality dalam mencari solusi terbaiknya untuk peningkatan Wawasan Nusantara $[1][4][5][6]$.

\section{METODE}

\subsection{Diagram Alir Kegiatan}

P2M diawali dengan melakukan kajian literatur berupa konsep teori yang relevan. Hasil kajian tersebut menjadi dasar untuk mengungkapkan permasalahan yang ada diseputar masalah lunturnya Wawasan Nusantara generasi muda, khususnya siswa sekolah dasar.

Untuk mendalami permasalahan, dilakukan observasi ke lapangan untuk mengetahui permasalahan dan data sesungguhnya yang terjadi di lapangan di Sekolah Global Prestasi School (GPS) khususnya pada Siswa SD kelas 5. Data awal akan dikumpulkan untuk analisa instrument skala pengukuran Wawasan Nusantara yang relevan dengan masalah pemahaman Wawasan Nusantara yang terjadi pada generasi muda khususnya siswa sekolah dasar kelas lima. Hasil dalam tahapan ini berupa model konten pemahaman Wawasan Nusantara berupa indikator-indikator pengukuran peningkatan Wawasan Nusantara berkaitan dengan permasalahan dalam pemberdayaan dan penguatan kesadaran berbangsa dan bernegara yang berlandaskan pada Pancasila, UUD 1945, Bhinneka Tunggal Ika, dan NKRI.

Berdasarkan model teoritis yang dihasilkan, maka dilakukan langkah analisis dan perancangan aplikasi pembelajaran. Pada tahap ini akan dilakukan analisis data hasil survey dan observasi dan perancangan aplikasi pembelajaran berbasis AR. Selanjutnya, dilanjutkan dengan proses pengembangan aplikasi. Serangkaian ujicoba akan dilakukan. Setelah aplikasi dinilai telah mencapai 
hasil yang diinginkan dan menjawab permasalahan maka dihasilkan sebuah aplikasi pembelajaran Wawasan Nusantara berbasis AR guna meningkatkan pemahaman Wawasan Nusantara generasi muda. Gambar 2. berikut merupakan diagam alur pelaksanaan P2M yang merangkum keseluruhan kegiatan pelaksanaan:

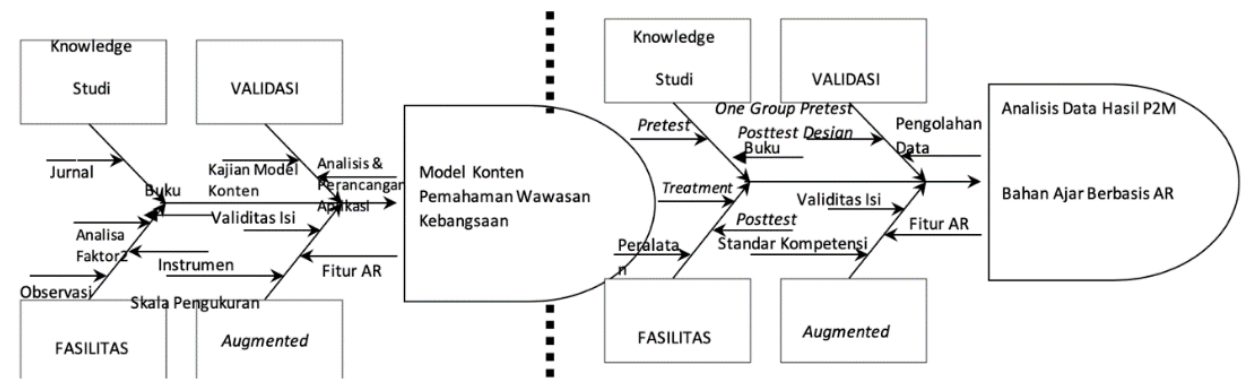

Gambar 2. Diagram Alur Pelaksanaan P2M

\section{HASIL DAN PEMBAHASAN}

Berdasarkan Nota Dinas 2946/3/A10/ND/2020 dari Dekan Fakultas Telematika Energi tertanggal 2 Maret 2020 untuk melakukan observasi pada tanggal 3 dan 4 Maret 2020. Hasil dari observasi yang dilakukan pada tanggal 3 dan 4 Maret 2020 tersebut adalah pertemuan dengan Kepala Sekolah GPS Bekasi yang biasa disapa dengan Mr. Anto, untuk membahas mengenai Proposal dan Pelaksanaan P2M.

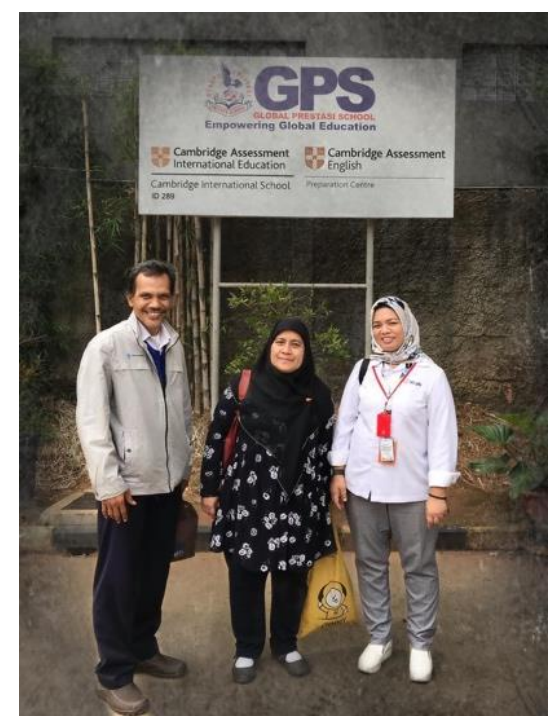

Gambar 3. Observasi Tim P2M ke SD GPS Bekasi

Hasil pertemuan dengan Kepala Sekolah Dasar adalah Pelaksanaan P2M dilaksanakan di Sekolah Dasar Global Prestasi (GPS) Bekasi kepada siswa kelas lima TA 2019/2020 yang berjumlah sebanyak 90 siswa pada tanggal 18, 19 Maret 2020. Kegiatan akan diawali dengan melakukan pretest, kemudian dilakukan pembelajaran menggunakan Aplikasi Pembelajaran Wawasan Nusantara pada mata pelajaran PKn dengan aplikasi berbasis AR yang sudah dihasilkan, persiapan pelaksanaan posttest dan pengolahan data hasil pretest dan posttest, dan melakukan pengolahan data dengan desain penelitian one group pretest posttest design terhadap hasil pembelajaran yang telah dilakukan. 
Sejak awal Maret 2020 wabah pandemic Covid 19 melanda negara kita, semua kegiatan pembelajaran tatap muka di sekolah GPS dihentikan mulai tanggl 16 Maret 2020 sampai dengan batas waktu yang belum diketahui menjadi kegiatan pembelajaran jarak jauh (PJJ). Akhirnya terkait dengan pandemi tersebut, Tim P2M terpaksa mengubah rencana kegiatan pembelajaran bagi siswa menjadi kegiatan yang pelaksanannya dilaksanakan secara online yaitu pelatihan pembelajaran bagi guru-guru SD dengan menggunakan Aplikasi Zoom Meeting pada tanggal 25 Juli 2020 yang bertempat di Lantai 5 Lab ITCC Institut Teknologi PLN, yang pelaksanaannya berlangsung selama dua jam, yaitu dimulai Pukul 13.00 sampai dengan pukul 15.00 WIB. Kegiatan pelatihan yang dilaksanakan secara online menggunakan Zoom meeting ini sukses menarik peserta dari berbagai wilayah di tanah air, di antaranya dari Jakarta, Depok, Tangerang, Bekasi, Sulawesi Tengah, dan Jawa Timur, lebih kurang lima puluh peserta hadir dalam pelatihan ini.

Berikut adalah leaflet serta link untuk acara pelaksanaan serta daftar nama peserta yang telah mendaftar.

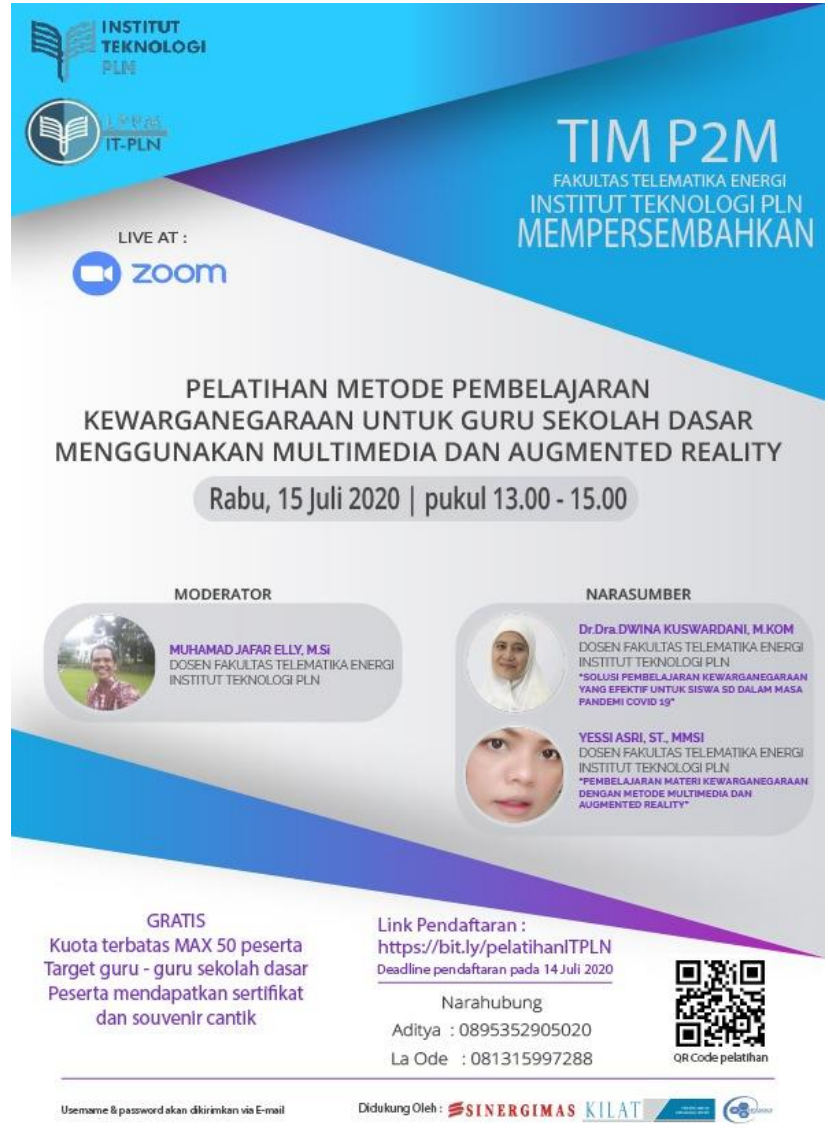

Gambar 4. Leaflet P2M via Zoom 
Terang: Jurnal Pengabdian Pada Masyarakat Menerangi Negeri

e-ISSN: 2655-5948

Vol. 3, No. 2, Juli 2021

P-ISSN: 2655-5956

DOI: https://doi.org/10.33322/terang.v3i2.1069

Hal. $177-191$

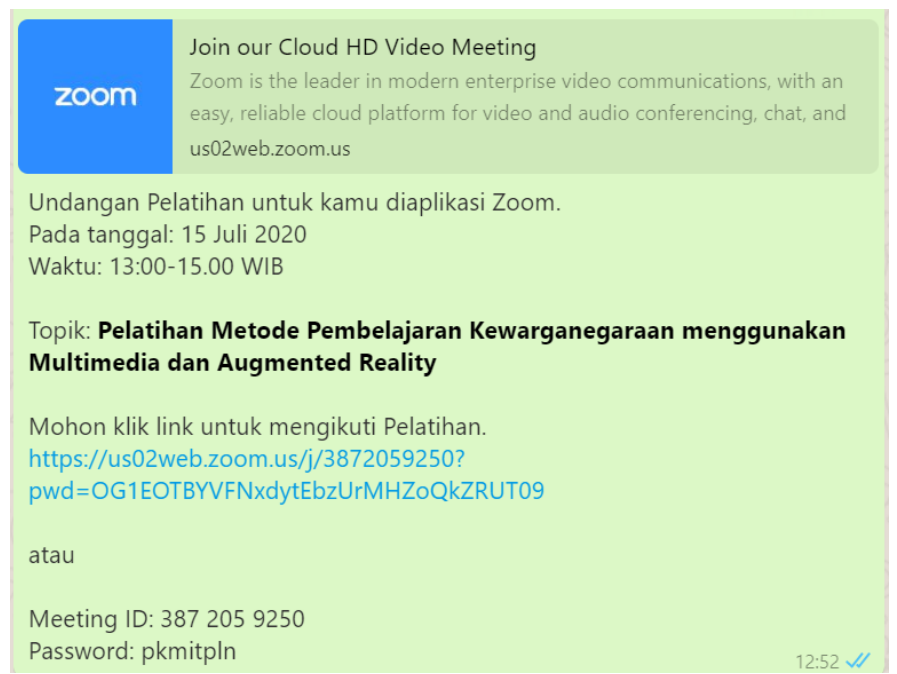

Gambar 5. Tempat, Tanggal, Waktu dan Link untuk Pelaksanaan Pelatihan P2M via Zoom 
Terang: Jurnal Pengabdian Pada Masyarakat Menerangi Negeri

e-ISSN: 2655-5948

Vol. 3, No. 2, Juli 2021

P-ISSN: 2655-5956

DOI: https://doi.org/10.33322/terang.v3i2.1069

Hal. $177-191$

Tabel 1. Daftar Peserta Pelatihan

DAFTAR PESERTA PELATIHAN

\begin{tabular}{|c|c|c|c|c|}
\hline No. & Timestamp & Nama & Alamat Tempat Tinggal & Institusi saat ini \\
\hline 1 & $\begin{array}{l}6 / 29 / 2020 \\
22: 25: 00\end{array}$ & $\begin{array}{l}\text { Hengki } \\
\text { Sikumbang }\end{array}$ & IT PLN & IT PLN \\
\hline 2 & $\begin{array}{l}6 / 30 / 2020 \\
8: 55: 36\end{array}$ & $\begin{array}{l}\text { Neni Risdiani, } \\
\text { Sp }\end{array}$ & $\begin{array}{l}\text { Perum Bunga Raya Blok F no } 7 \\
\text { Bekasi Timur }\end{array}$ & - \\
\hline 3 & $\begin{array}{l}6 / 30 / 2020 \\
9: 10: 33\end{array}$ & Nur Hasanah & $\begin{array}{l}\text { Jl.tambuli desa lolu kec.sigi } \\
\text { biromaru kab. Sigi SULTENG }\end{array}$ & $\begin{array}{l}\text { SDIT Insan } \\
\text { Gemilang }\end{array}$ \\
\hline 4 & $\begin{array}{l}6 / 30 / 2020 \\
12: 34: 40\end{array}$ & Sukini & $\begin{array}{l}. J 1 . \text { Benda .07/02 Limo, Limo } \\
\text { DepoDepok. }\end{array}$ & KBKS kak Seto \\
\hline 5 & $\begin{array}{l}7 / 1 / 2020 \\
10: 40: 31\end{array}$ & Reva Juwita & Jl Arabika Atas No. 30 & $\begin{array}{l}\text { SDN Pondok } \\
\text { Kopi 08 Pagi }\end{array}$ \\
\hline 6 & $\begin{array}{l}7 / 1 / 2020 \\
11: 14: 34 \\
\end{array}$ & Sarwoyuwono & $\begin{array}{l}\text { JL. PADAT KARYA NO. } 33 \text { RT. } \\
\text { 08/01 PONDOK KELAPA } \\
\text { JAKARTA TIMUR }\end{array}$ & $\begin{array}{l}\text { SDN PONDOK } \\
\text { KELAPA } 09\end{array}$ \\
\hline 7 & $\begin{array}{l}7 / 1 / 2020 \\
11: 24: 32\end{array}$ & $\begin{array}{l}\text { Rika Purnawati, } \\
\text { S. Pd }\end{array}$ & $\begin{array}{l}\text { Kav. Nusantara JL. Nusantara III } \\
\text { RT. 012/022 no. } 32 \text { harapan Jaya } \\
\text { Bekasi Utara }\end{array}$ & $\begin{array}{l}\text { SDN Pondok } \\
\text { Kelapa } 09\end{array}$ \\
\hline 8 & $\begin{array}{l}7 / 1 / 2020 \\
11: 32: 00\end{array}$ & Hj. Fatonih & $\begin{array}{l}\text { Jln. Wibawa Mukti IV. Kav. BNI. } \\
\text { No. 150. RT03/RW01. Kel. } \\
\text { Jatimekar. Kec. Jatiasih. Bekasi }\end{array}$ & $\begin{array}{l}\text { Sdn Pondok } \\
\text { Kelapa } 09\end{array}$ \\
\hline 9 & $\begin{array}{l}7 / 1 / 2020 \\
11: 46: 27\end{array}$ & Mursidah & $\begin{array}{l}\text { Kp.Gandaria rt001/07 no.213 } \\
\text { kel.pondok Kelapa Jaktim }\end{array}$ & $\begin{array}{l}\text { SDN Pondok } \\
\text { Kelapa O9 }\end{array}$ \\
\hline 10 & $\begin{array}{l}7 / 1 / 2020 \\
11: 59: 15\end{array}$ & Sukandar & $\begin{array}{l}\text { Jl.kko Usman dan Harun no } 52 \\
\text { Jakarta pusat }\end{array}$ & $\begin{array}{l}\text { Disnakertrans dan } \\
\text { energi dki jakarta }\end{array}$ \\
\hline 11 & $\begin{array}{l}7 / 1 / 2020 \\
12: 33: 22\end{array}$ & Sumini & $\begin{array}{l}\text { KomKar DKI Blok P3/20 Rt } 20 \text { Rw } \\
02 \\
\text { Pondok Kelapa, Duren Sawit, Jak } \\
\text { Tim. }\end{array}$ & $\begin{array}{l}\text { SDN PONDOK } \\
\text { KELAPA } 09 \\
\text { PAGI }\end{array}$ \\
\hline 12 & $\begin{array}{l}7 / 1 / 2020 \\
12: 44: 10\end{array}$ & $\begin{array}{l}\text { Pimar Aprilo } \\
\text { Jujur Perkasa }\end{array}$ & $\begin{array}{l}\text { Jln. H. Mali rt 11, rw 1, no } 40 \text {, } \\
\text { Cengkareng, Jakarta Barat, DKI } \\
\text { Jakarta, } 11750 .\end{array}$ & IT - PLN Jakarta \\
\hline 13 & $\begin{array}{l}7 / 1 / 2020 \\
12: 46: 51\end{array}$ & $\begin{array}{l}\text { Yuliana } \\
\text { Suminem, } \\
\text { S.Pd.Sd } \\
\end{array}$ & $\begin{array}{l}\text { Perum Pejuang Pratama, jln. } \\
\text { Pratama } 17 \text { blok AN no. 3, Medan } \\
\text { Satria, Bekasi }\end{array}$ & $\begin{array}{l}\text { SDN PONDOK } \\
\text { KELAPA } 09 \\
\text { JAKARTA } \\
\end{array}$ \\
\hline 14 & $\begin{array}{l}7 / 1 / 2020 \\
13: 28: 26 \\
\end{array}$ & $\begin{array}{l}\text { Fatahilah } \\
\text { Sutawiyono, S. } \\
\mathrm{Pd}\end{array}$ & $\begin{array}{l}\text { J1. Raya Condet, Gang Masjid Al } \\
\text { Hawi 2, RT/RW 006/005, Cililitan, } \\
\text { Kramatjati, Jakarta Timur }\end{array}$ & $\begin{array}{l}\text { SDN Tegal } \\
\text { Parang 05 Jakarta } \\
\text { Selatan }\end{array}$ \\
\hline 15 & $\begin{array}{l}7 / 1 / 2020 \\
13: 43: 59 \\
\end{array}$ & Fandhi & $\begin{array}{l}\text { Pondok ungu permai sektor } 5 \text { Blok } \\
\text { R2 No.6 Bekasi }\end{array}$ & $\begin{array}{l}\text { SDIT Al } \\
\text { Husnayain }\end{array}$ \\
\hline 16 & $\begin{array}{l}7 / 1 / 2020 \\
13: 51: 52\end{array}$ & $\begin{array}{l}\text { Yuanita } \\
\text { Rismania Aspi }\end{array}$ & Jl. Mawar Dalam 3 Bintaro & $\begin{array}{l}\text { SDN BINTARO } \\
14 \text { Pagi }\end{array}$ \\
\hline
\end{tabular}


Terang: Jurnal Pengabdian Pada Masyarakat Menerangi Negeri

e-ISSN: 2655-5948

Vol. 3, No. 2, Juli 2021

P-ISSN: 2655-5956

DOI: https://doi.org/10.33322/terang.v3i2.1069

Hal. $177-191$

\begin{tabular}{|c|c|c|c|c|}
\hline 17 & $\begin{array}{l}7 / 3 / 2020 \\
19: 52: 07\end{array}$ & Nurjanah & $\begin{array}{l}\text { Jln menjangan 1D Rt } 03 \text { Rwa } 01 \\
\text { pondok Ranji ciputat timur } \\
\text { Tangerang Selatan Banten }\end{array}$ & $\begin{array}{l}\text { SDIT Nur } \\
\text { Fatahillah }\end{array}$ \\
\hline 18 & $\begin{array}{l}7 / 3 / 2020 \\
19: 53: 18\end{array}$ & Sri Rahayu & $\begin{array}{l}\text { Kedaung Pamulang Tangerang } \\
\text { Selatan }\end{array}$ & Sdit nurfatahillah \\
\hline 19 & $\begin{array}{l}7 / 3 / 2020 \\
20: 04: 27\end{array}$ & $\begin{array}{l}\text { Arhis Dwi } \\
\text { Prabowo }\end{array}$ & $\begin{array}{l}\text { Pamulang permai timur jalan delima } \\
\text { raya blok b39 no } 11 \text { Pamulang } \\
\text { Tangerang Selatan }\end{array}$ & $\begin{array}{l}\text { SDIT NUR } \\
\text { FATAHILLAH }\end{array}$ \\
\hline 20 & $\begin{array}{l}7 / 3 / 2020 \\
20: 15: 04\end{array}$ & Isdiana & $\begin{array}{l}\text { Bumi Puspiptek Asri sektor } 4 \text { blok s } \\
\text { no } 12 \text { Pagedangan Tangeramg }\end{array}$ & $\begin{array}{l}\text { SDIT Nur } \\
\text { Fatahillah }\end{array}$ \\
\hline 21 & $7 / 8 / 2020$ 6:26:50 & $\begin{array}{l}\text { Dena Aryani } \\
\text { Putri, S.Pd.I }\end{array}$ & $\begin{array}{l}\text { Jl. Waru Jaya IV no. } 65 \text { Rt 001/022, } \\
\text { Kel. Mekarjaya, Kec. Sukmajaya } \\
\text { Depok }\end{array}$ & $\begin{array}{l}\text { SDI Al Azhar } 46 \\
\text { GDC }\end{array}$ \\
\hline 22 & $7 / 8 / 2020$ 8:57:36 & Siti Nurwandari & $\begin{array}{l}\text { Perumahan Ambar Cibinong } \\
\text { Residence blok A5 No } 4\end{array}$ & $\begin{array}{l}\text { SDI Al Azhar } 46 \\
\text { GDC }\end{array}$ \\
\hline 23 & $\begin{array}{l}7 / 8 / 2020 \\
17: 38: 51\end{array}$ & Dyah Sukowati & $\begin{array}{l}\text { Jl. KSU Kalimulya Perum. Taman } \\
\text { Anyelir3 Blok H2 No.7 Rt.001 } \\
\text { Rw.011 Kel. Kalimulya Kec. } \\
\text { Cilodong, Depok }\end{array}$ & Al Azhar 46 GDC \\
\hline 24 & $\begin{array}{l}7 / 10 / 2020 \\
17: 52: 56\end{array}$ & Dewi Ratna Asih & $\begin{array}{l}\text { Blok Tengki } 2 \text { no } 20 \text { RT } 01 \text { RW } 10 \\
\text { Meruyung Limo Depok }\end{array}$ & KBKS Kak Seto \\
\hline 25 & $\begin{array}{l}7 / 12 / 2020 \\
12: 50: 17\end{array}$ & Tiya Octa Mulia & Jl. Cabe 3 no 6 & $\begin{array}{l}\text { SDN pondok cabe } \\
\text { Ilir } 01\end{array}$ \\
\hline 26 & $\begin{array}{l}7 / 12 / 2020 \\
12: 53: 39\end{array}$ & $\begin{array}{l}\text { Septa Apriyani } \\
\text { Maulina., S.Pd }\end{array}$ & $\begin{array}{l}\text { Perumahan taman Bougainvillea } \\
\text { Blok B no } 12 \text { A jl masjid Al } \\
\text { Muhajirin Cinangka sawangan } \\
\text { Depok }\end{array}$ & $\begin{array}{l}\text { SDN REMPOA } \\
03\end{array}$ \\
\hline 27 & $\begin{array}{l}7 / 12 / 2020 \\
16: 41: 01\end{array}$ & Nunuy Nuryani & $\begin{array}{l}\text { Perum. Simprug De Poris, Jl. } \\
\text { Mangga 2, E7/25 Tangerang }\end{array}$ & $\begin{array}{l}\text { SDN Kapuk } 08 \\
\text { Petang }\end{array}$ \\
\hline 28 & $\begin{array}{l}7 / 12 / 2020 \\
17: 37: 30\end{array}$ & Eni Purbowati & $\begin{array}{l}\text { Kp. Sawah Indah RT } 01 \text { RW } 09 \\
\text { Bojonggede }\end{array}$ & $\begin{array}{l}\text { SDIT } \\
\text { Misbahussudur }\end{array}$ \\
\hline 29 & $\begin{array}{l}7 / 13 / 2020 \\
23: 53: 45\end{array}$ & $\begin{array}{l}\text { Wahyu Eko } \\
\text { Ramdhany S.Pd }\end{array}$ & $\begin{array}{l}\text { Jln.kavking keuangan raya kedaung } \\
\text { ciputat }\end{array}$ & SDN Rempoa 03 \\
\hline 30 & $\begin{array}{l}7 / 14 / 2020 \\
10: 59: 28\end{array}$ & $\begin{array}{l}\text { Mochammad } \\
\text { Ikhsan } \\
\text { Ubaydillah }\end{array}$ & $\begin{array}{l}\text { Dan.Sumberingin II, RT.03 RW.07, } \\
\text { Ds.Sumbersuko, Kec.Gempol, } \\
\text { Kab.Pasuruan, Jawa Timur }\end{array}$ & $\begin{array}{l}\text { SMKN } 1 \\
\text { GEMPOL }\end{array}$ \\
\hline 31 & $\begin{array}{l}7 / 14 / 2020 \\
11: 22: 19\end{array}$ & $\begin{array}{l}\text { Hanna Septiani } \\
\text { Rumahorbo }\end{array}$ & $\begin{array}{l}\text { Jl.Haji Ulakma Sinaga,Rambung } \\
\text { Merah,Sumatera Utara }\end{array}$ & $\begin{array}{l}\text { IT PLN } \\
\text { JAKARTA }\end{array}$ \\
\hline 32 & $\begin{array}{l}7 / 14 / 2020 \\
11: 41: 30\end{array}$ & Kevin & $\begin{array}{l}\text { Kp.Lagoa RT/RW:001/011 No.43 } \\
\text { SETIA } \\
\text { MULYA,TARUMAJAYA,BEKASI }\end{array}$ & $\begin{array}{l}\text { INSTITUT } \\
\text { TEKNOLOGO - } \\
\text { PLN }\end{array}$ \\
\hline 33 & $\begin{array}{l}7 / 14 / 2020 \\
11: 54: 08\end{array}$ & $\begin{array}{l}\text { AGUNG } \\
\text { PRAYOGA }\end{array}$ & $\begin{array}{l}\text { Jl Cimuncang Cilik RT 04/Rw } \\
\text { 014,Kel Cimuncang, kec Serang } \\
\text { Banten }\end{array}$ & STT PLN \\
\hline
\end{tabular}


Terang: Jurnal Pengabdian Pada Masyarakat Menerangi Negeri

e-ISSN: 2655-5948

Vol. 3, No. 2, Juli 2021

P-ISSN: 2655-5956

DOI: https://doi.org/10.33322/terang.v3i2.1069

Hal. $177-191$

\begin{tabular}{|c|c|c|c|c|}
\hline 34 & $\begin{array}{l}7 / 14 / 2020 \\
12: 29: 21\end{array}$ & $\begin{array}{l}\text { MOCHAMMAD } \\
\text { IKHSAN } \\
\text { UBAYDILLAH }\end{array}$ & $\begin{array}{l}\text { Dan.Sumberingin II, RT.03 RW.07, } \\
\text { Ds.Sumbersuko, Kec.Gempol, } \\
\text { Kab.Pasuruan, Jawa Timur }\end{array}$ & $\begin{array}{l}\text { SMKN } 1 \\
\text { GEMPOL }\end{array}$ \\
\hline 35 & $\begin{array}{l}7 / 14 / 2020 \\
12: 46: 07\end{array}$ & Ahmad Zaki & Padang & IT PLN \\
\hline 36 & $\begin{array}{l}\text { 7/14/2020 } \\
13: 08: 19\end{array}$ & $\begin{array}{l}\text { Okki Dwi } \\
\text { Aditama }\end{array}$ & Pati, Jawa Tengah & $\begin{array}{l}\text { Institut Teknik } \\
\text { PLN }\end{array}$ \\
\hline 37 & $\begin{array}{l}7 / 14 / 2020 \\
15: 34: 06\end{array}$ & $\begin{array}{l}\text { Givari Fairus } \\
\text { Ferdiansyah Deu }\end{array}$ & JL.Nani Wartabone no.34 & $\begin{array}{l}\text { Institut Teknologi } \\
\text { PLN }\end{array}$ \\
\hline 38 & $\begin{array}{l}7 / 14 / 2020 \\
17: 09: 09\end{array}$ & $\begin{array}{l}\text { MIFTARINI } \\
\text { JUNIARTI, S. } \\
\text { Pd }\end{array}$ & $\begin{array}{l}\text { Jl. Palem Barat II Pondok Pekayon } \\
\text { Indah Blok CC. } 10 \text { No. 10, Bekasi } \\
\text { Selatan } 17148\end{array}$ & $\begin{array}{l}\text { SDN PONDOK } \\
\text { KELAPA } 09\end{array}$ \\
\hline 39 & $\begin{array}{l}7 / 14 / 2020 \\
18: 13: 42\end{array}$ & IRHAMAH & $\begin{array}{l}\text { Kampung Lette RW 04/RT } 05 \text { Kel. } \\
\text { Tanjung Merdeka Kota Makassar } \\
\text { Provinsi Sul-Sel }\end{array}$ & $\begin{array}{l}\text { SD NEGERI } \\
\text { BAYANG }\end{array}$ \\
\hline 40 & $\begin{array}{l}7 / 14 / 2020 \\
19: 26: 45\end{array}$ & Irsyadah Ibrahim & Jl.H.Ibrahim sultan dg tutu & $\begin{array}{l}\text { SD NEGERI } \\
\text { BAYANG }\end{array}$ \\
\hline
\end{tabular}

Solusi metode pembelajaran kepada peserta pelatihan yang sebagian besar adalah guru sekolah dasar dari berbagai wilayah di Indonesia. Sebagai nara sumber pertama adalah Dr. Dra. Dwina Kuswardani, MKom., menguraikan secara gamblang bagaimana mengatasi masalah pembelajaran kewarganegaraan kepada siswa SD. Sulitnya memberikan pemahaman ini karena siswa mempunyai gaya belajar yang berbeda. Gaya belajar tersebut meliputi gaya belajar visual, auditori dan kinestetik. Siswa sekolah dasar kini masuk dalam generasi digital. Oleh karena itu, pembelajaran yang efektif dengan menggunakan media yang tidak hanya teks tetapi ada gambar, video, audio, digital story telling creator dan komunikasi grup. Kombinasi inilah yang disebut Multimedia, misalnya flash flip book dan augemnted reality. Sementara itu, nara sumber yang kedua yaitu Yessy Asri, ST., MMSI. memaparkan tentang pemnfaatan teknologi multimedia dan augmented reality dalam bentuk aplikasi siap pakai. Teknologi ini sebelumnya sudah diterapkan di beberapa sekolah dasar di Bekasi. Hasilnya ada peningkatan pengetahuan dan pemahaman peserta didik ketika menggunakan pendekatan teknologi tersebut. Sistem aplikasi pembelajaran kewarganegaraan ini berisi pengetahuan tentang wawasan kebangsaan mulai dari Negara Kesatuan Republik Indonesia (NKRI), Pancasila, Bhineka Tunggal Ika, wawasan nusantara, sejarah bangsa, para tokoh dan pahlawan bangsa, kekayaan seni budaya, wisata, biodiversitas dan sebagainya. Secara garis besar, muatan materinya mencakup tiga hal utama yang saling berhubungan dalam proses pembelajaran, yakni belajar, bermain dan latihan. Ketiga hal tersebut disajikan dengan mudah dan menarik dengan kombinasi teks, gambar, suara, animasi dan video. Cara ini diharapkan dapat menarik minat para siswa SD untuk belajar dan memahami tentang kewarganegaraan dan wawasan kebangsaan Indonesia. Adapun susunan acara pelaksanaan pelatihan ini adalah sebagai berikut: 
Terang: Jurnal Pengabdian Pada Masyarakat Menerangi Negeri

e-ISSN: 2655-5948

Vol. 3, No. 2, Juli 2021

P-ISSN: 2655-5956

DOI: https://doi.org/10.33322/terang.v3i2.1069

Hal. 177 - 191

AGENDA

PELATIHAN METODE PEMBELAJARAN KEWARGANEGARAAN

UNTUK GURU-GURU SEKOLAH DASAR MENGGUNAKAN MULTIMEDIA DAN REALITY AUGMENTED

JAKARTA, RABU, 15 JULI 2020

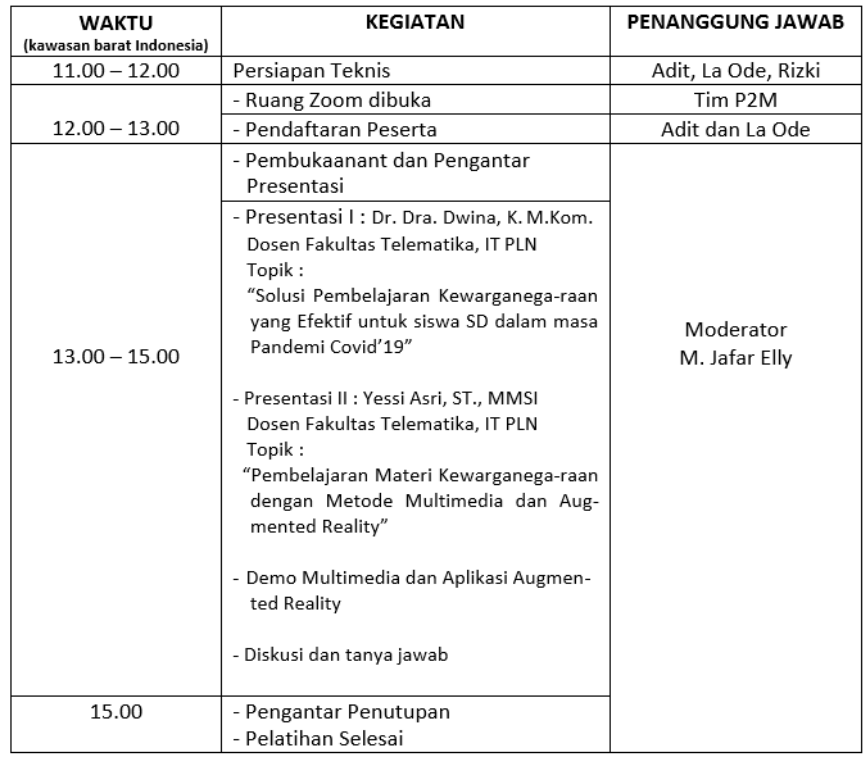

Gambar 6. Agenda Pelaksanaan Pelatihan via Zoom
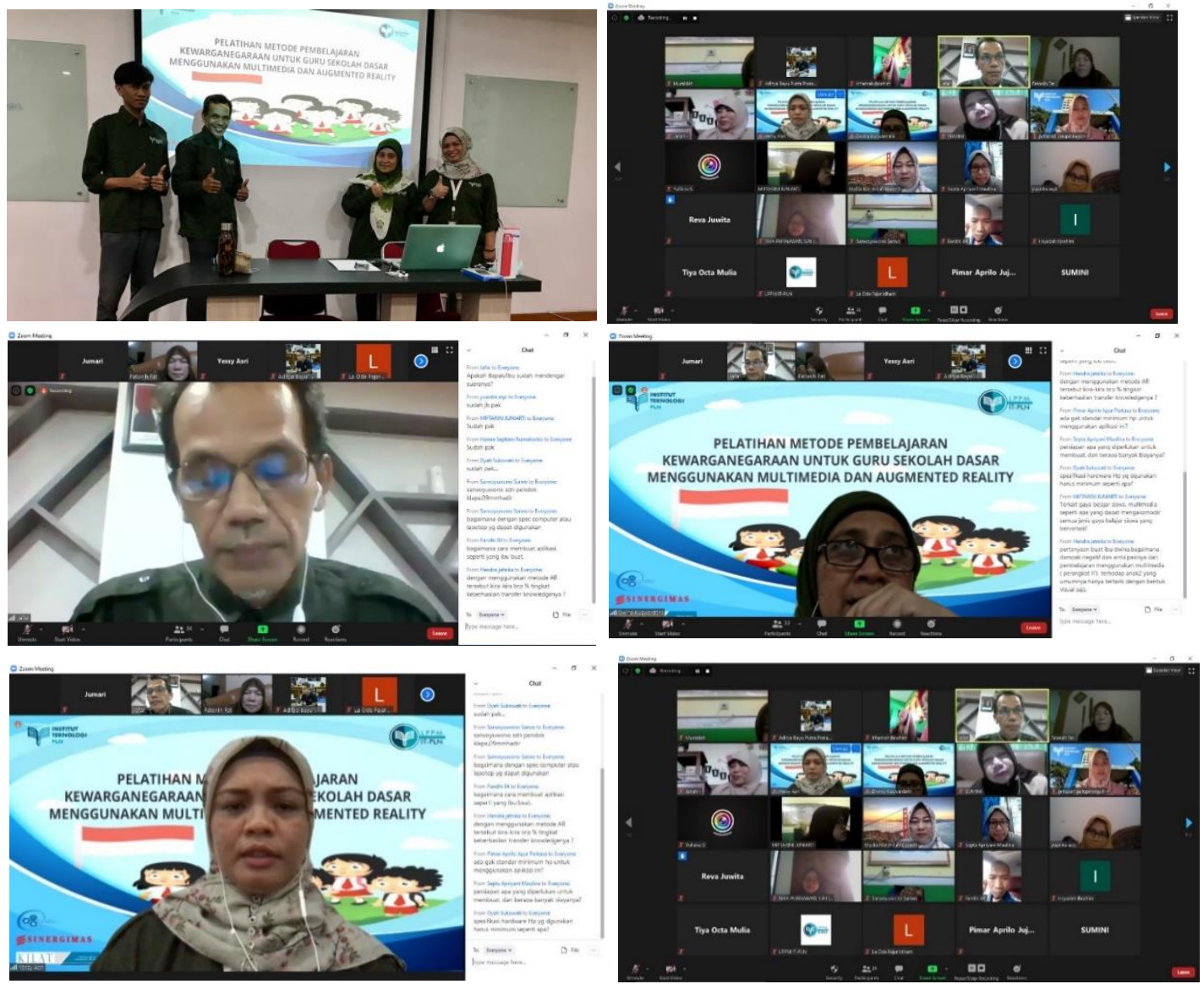

Gambar 7. Foto Dokumentasi Pelaksanaan Pelatihan Via Zoom 
Terang: Jurnal Pengabdian Pada Masyarakat Menerangi Negeri

Tabel 2. Saran dan Masukan dari Peserta

\begin{tabular}{|cl|}
\hline No. & \multicolumn{1}{c|}{ Saran \& Masukan } \\
\hline 1 & Peserta diberikan praktek langsung \\
\hline 2 & $\begin{array}{l}\text { Persiapan sarana yg diperlukan hrs lbh siap sehingga tdk ada kendala ketika } \\
\text { pelaksanaan terutama Audio }\end{array}$ \\
\hline 3 & Sebaiknya diberikan tutorialnya \\
\hline 4 & Harus ada link alternatif seperti YouTube \\
\hline 5 & Materi nya menarik \\
\hline 6 & Agar kegiatan ini bisa berkelanjutan \\
\hline 7 & Waktu pelatihan sudah tepat, smoga ada pelatihan untuk mapel lain \\
\hline 8 & Membuat pelatihan tentang pembuatan video pembelajaran Matematika \\
\hline 9 & Sarana dan prasarana lbh dipersiapkan lagi terutama di audio \\
\hline 10 & Semoga lebih baik lagi \\
\hline 11 & $\begin{array}{l}\text { kalo bisa aplikasinya tidak hanya pelajaran kewarganegaraan tapi bisa juga } \\
\text { diterapkan kedalam pelajaran lain seperti IPA atau IPS }\end{array}$ \\
\hline No. & \\
\hline & $\begin{array}{l}\text { Sudah baik.. Mudah-mudahan pelatihan seperti ini sering diadakan dengan } \\
\text { tema yg bervariasi.. }\end{array}$ \\
\hline 12 & $\begin{array}{l}\text { Pertemuannya sangat menarik, kiranya bapak ibu bersedia mengadakan } \\
\text { pertemuan bagaimana sebuah aplikasi bekerja }\end{array}$ \\
\hline 14 & Pemaparan nya tdk terlalu cepat . \\
\hline 15 & $\begin{array}{l}\text { Alangkah baiknya berlaku jg untuk siswa sd yg kelas rendah seperti kls 1,2 } \\
\text { atau } 3\end{array}$ \\
\hline 16 & Tetap semangat \\
\hline 17 & $\begin{array}{l}\text { sebenarnya lebih baik kita praktek langsung dalam menggunakan AR, tapi } \\
\text { memang terkendala karena tidak tatap muka }\end{array}$ \\
\hline 18 & Agar ada lagi pelatihan seperti ini.. \\
\hline & $\begin{array}{l}\text { Lebih ditingkatkat lagi jaringan internetnya saat memaparkan materi, sehingga } \\
\text { tdk keluar masuk atau bahkan putus2. Dan sebelum materi d paparkan }\end{array}$ \\
\hline
\end{tabular}

Tabel 3. Feedback dari Peserta

\begin{tabular}{|c|l|c|c|c|c|c|c|c|}
\hline No. & \multicolumn{1}{|c|}{ Nama } & $\begin{array}{c}\text { Kualitas } \\
\text { Audio }\end{array}$ & $\begin{array}{c}\text { Kualitas } \\
\text { Tampilan } \\
\text { Video }\end{array}$ & $\begin{array}{c}\text { Performance } \\
\text { \& Materi }\end{array}$ & $\begin{array}{c}\text { Membantu } \\
\text { Metode } \\
\text { Pembelajaran }\end{array}$ & $\begin{array}{c}\text { Kualitas } \\
\text { Pelayanan } \\
\text { Kegiatan }\end{array}$ & $\begin{array}{c}\text { Kesan \& } \\
\text { Penilaian } \\
\text { Kegiatan }\end{array}$ & $\begin{array}{c}\text { Bersedia } \\
\text { Ikut } \\
\text { Kegiatan } \\
\text { Kembali }\end{array}$ \\
\hline 1 & Nurjanah & Baik & Baik & Baik & Baik & Baik & Baik & Ya \\
\hline 2 & Sarwoyuwono & Cukup & Baik & Baik & Baik & Baik & Baik & Ya \\
\hline 3 & Yayuk & Baik & Baik & Baik & Baik & Cukup & Baik & Ya \\
\hline & $\begin{array}{l}\text { Fatahilah } \\
\text { Sutawiyono, S. Pd }\end{array}$ & $\begin{array}{c}\text { Baik } \\
\text { Sekali }\end{array}$ & $\begin{array}{c}\text { Baik } \\
\text { Sekali }\end{array}$ & Baik Sekali & Baik Sekali & $\begin{array}{c}\text { Baik } \\
\text { Sekali }\end{array}$ & $\begin{array}{c}\text { Baik } \\
\text { Sekali }\end{array}$ & Ya \\
\hline
\end{tabular}


Terang: Jurnal Pengabdian Pada Masyarakat Menerangi Negeri

e-ISSN: 2655-5948

Vol. 3, No. 2, Juli 2021

P-ISSN: 2655-5956

DOI: https://doi.org/10.33322/terang.v3i2.1069

Hal. $177-191$

\begin{tabular}{|c|c|c|c|c|c|c|c|c|}
\hline 5 & Ahmad Zaki & $\begin{array}{c}\text { Baik } \\
\text { Sekali }\end{array}$ & $\begin{array}{c}\text { Baik } \\
\text { Sekali }\end{array}$ & Baik Sekali & Baik Sekali & $\begin{array}{l}\text { Baik } \\
\text { Sekali }\end{array}$ & $\begin{array}{l}\text { Baik } \\
\text { Sekali }\end{array}$ & Ya \\
\hline 6 & Fandhi, S.Pd & $\begin{array}{c}\text { Baik } \\
\text { Sekali }\end{array}$ & $\begin{array}{c}\text { Baik } \\
\text { Sekali }\end{array}$ & Baik Sekali & Baik & $\begin{array}{c}\text { Baik } \\
\text { Sekali }\end{array}$ & $\begin{array}{c}\text { Baik } \\
\text { Sekali }\end{array}$ & Ya \\
\hline 7 & $\begin{array}{l}\text { Yuliana Suminem } \\
\text {,S.Pd.Sd }\end{array}$ & Baik & $\begin{array}{c}\text { Baik } \\
\text { Sekali }\end{array}$ & Baik & Baik Sekali & Baik & Baik & $\mathrm{Ya}$ \\
\hline 8 & Irhamah & $\begin{array}{c}\text { Baik } \\
\text { Sekali }\end{array}$ & Baik & Baik Sekali & Baik & $\begin{array}{c}\text { Baik } \\
\text { Sekali }\end{array}$ & Baik & Ya \\
\hline 9 & Sarwoyuwono & Cukup & Baik & Baik & Baik & Baik & Baik & Ya \\
\hline 10 & $\begin{array}{l}\text { Erlina Dian } \\
\text { Nugraheni, S. Pd }\end{array}$ & Baik & Baik & Baik & Baik & Baik & Baik & $\mathrm{Ya}$ \\
\hline 11 & $\begin{array}{l}\text { Rika Purnawati, } \\
\text { S.Pd }\end{array}$ & Baik & Baik & Baik & Baik & $\begin{array}{c}\text { Baik } \\
\text { Sekali }\end{array}$ & $\begin{array}{c}\text { Baik } \\
\text { Sekali }\end{array}$ & Ya \\
\hline 12 & $\begin{array}{l}\text { Miftarini Juniarti, } \\
\text { S. Pd }\end{array}$ & Baik & Baik & Baik Sekali & Baik & $\begin{array}{c}\text { Baik } \\
\text { Sekali }\end{array}$ & Baik & $\mathrm{Ya}$ \\
\hline 13 & $\begin{array}{l}\text { Hanna Septiani } \\
\text { Rumahorbo }\end{array}$ & Baik & Baik & Baik & Baik Sekali & $\begin{array}{c}\text { Baik } \\
\text { Sekali }\end{array}$ & $\begin{array}{c}\text { Baik } \\
\text { Sekali }\end{array}$ & Ya \\
\hline 14 & Isdiana & $\begin{array}{c}\text { Baik } \\
\text { Sekali }\end{array}$ & Cukup & Baik & Baik Sekali & Baik & Baik & Ya \\
\hline 15 & Fatonih & Baik & Baik & Baik & Baik & Baik & Baik & $\mathrm{Ya}$ \\
\hline 16 & Agung Prayoga & $\begin{array}{c}\text { Baik } \\
\text { Sekali }\end{array}$ & $\begin{array}{c}\text { Baik } \\
\text { Sekali }\end{array}$ & Baik Sekali & Baik & $\begin{array}{c}\text { Baik } \\
\text { Sekali }\end{array}$ & Baik & Ya \\
\hline 17 & $\begin{array}{l}\text { Yuanita Rismania } \\
\text { Aspi, S.Pd }\end{array}$ & Baik & $\begin{array}{c}\text { Baik } \\
\text { Sekali }\end{array}$ & Baik Sekali & Baik & $\begin{array}{c}\text { Baik } \\
\text { Sekali }\end{array}$ & $\begin{array}{c}\text { Baik } \\
\text { Sekali }\end{array}$ & Ya \\
\hline 18 & $\begin{array}{l}\text { Septa Apriyani } \\
\text { Maulina., S.Pd }\end{array}$ & Baik & $\begin{array}{c}\text { Baik } \\
\text { Sekali }\end{array}$ & Baik Sekali & Baik & $\begin{array}{c}\text { Baik } \\
\text { Sekali }\end{array}$ & Baik & $\mathrm{Ya}$ \\
\hline 19 & Mursidah & Baik & Baik & Baik Sekali & Baik & Baik & Baik & $\begin{array}{l}\text { Ragu- } \\
\text { Ragu }\end{array}$ \\
\hline 20 & Dyah Sukowati & Baik & $\begin{array}{c}\text { Kurang } \\
\text { Baik }\end{array}$ & Baik Sekali & Baik & Baik & Baik & Ya \\
\hline
\end{tabular}

Kegiatan pelatihan yang dilaksanakan secara online menggunakan Aplikasi Zoom ini sukses menarik peserta dari berbagai wilayah di tanah air, di antaranya dari Jakarta, Depok, Tangerang, Bekasi, Sulawesi Tengah, dan Jawa Timur. Lebih kurang lima puluh peserta hadir dalam pelatihan tersebut beserta perwakilan dari LPPM, Dekan Fakultas Telematika Energi, Kepala Laboratorium ITCC IT PLN, Kepala PDSI IT PLN, serta dosen-dosen dari Fakultas Telematika Energi. Tim pengabdian kepada masyarakat terdiri atas tiga orang dosen dari fakultas Telematika Energi, yakni Yessy Asri sebagai Ketua tim, Dwina Kuswardani dan Muhamad Jafar Elly sebagai Anggota serta melibatkan tiga orang mahasiswa dari Jurusan Informatika, masing-masing adalah La Ode, Aditya dan Jumari.

\section{KESIMPULAN}

Berdasarkan hasil analisis data dan pembahasan yang telah diuraikan pada bab-bab sebelumnya, dapat dikemukakan kesimpulan sebagai berikut.

1. Pada proses pembelajaran, seorang Guru harus dapat menguasai dan memilih media pembelajaran yang tepat untuk digunakan pada proses pembelajaran. Hal tersebut bertujuan agar materi pembelajaran yang diberikan akan diterima dengan baik oleh siswa, sehingga proses pembelajaran akan berlangsung efektif. 
2. Penggunaan multimedia Flip Book dan Augmented Reality dalam mata pelajaran Pendidikan Kewarganegaraan ini bertujuan agar Guru/Siswa dapat dengan mudah menyampaikan/menerima materi pembelajaran, sehingga dapat menarik minat belajar siswa dalam pembelajaran dalam menanamkan nilai-nilai kebudayaan dan sejarah bangsanya untuk mampu menumbuhkan jiwa nasionalisme sedini mungkin pada diri anakanak.

3. Sistem aplikasi pembelajaran kewarganegaraan ini secara garis besar muatan materinya mencakup tiga hal utama yang saling berhubungan dalam proses pembelajaran, yakni belajar, bermain dan latihan. Ketiga hal tersebut disajikan dengan mudah dan menarik dengan kombinasi teks, gambar, suara, animasi dan video.

4. Kegiatan pelatihan yang dilaksanakan secara online menggunakan Aplikasi Zoom ini sukses menarik peserta dari berbagai wilayah di tanah air yang ditargetkan kepada Guruguru Sekolah Dasar di tengah Pandemic Covid 19 saat ini yang rasanya tidak mudah memberikan pengetahuan dan pemahaman kewarnegaraan kepada para siswa SD menggunakan cara-cara konvensional seperti masa sebelum pandemic.

5. Selain menghasilkan Aplikasi Pembelajaran Kewarganegaraan Berbasis Multimedia dan Augmented Reality, Tim P2M kami juga menghasilkan Diktat Ajar Kewarganegaraan berbasis Augmented Reality yang dapat didownload di link https://bit.ly/modul_wki.

6. Aplikasi Pembelajaran Kewarganegaraan Berbasis Multimedia dan Augmented Reality ini dapat didownload melalui playstore dengan link http://bit.ly/aplikasi_wki dan link untuk Marker https://bit.ly/modulwki

\section{SARAN}

Berdasarkan hasil feedback yang diberikan oleh para peserta ada beberapa saran-saran dalam pengembangan kegiatan selanjutnya, yaitu:

1. Agar Pelatihan yang diberikan disertai dengan Praktek langsung kepada para peserta, mulai dari tahapan pembuatan aplikasi sampai kepada penggunaan aplikasi.

2. Agar sarana dan prasarana lebih ditingkatkan lagi terutama audio dan jaringan, agar selama proses pembelajaran via Zoom ini dapat berjalan dengan lebih baik.

3. Agar kegiatan seperti ini dapat berkelanjutan guna lebih meningkatkan proses pembelajaran.

\section{UCAPAN TERIMA KASIH}

Terimakasih yang sebesar-besarnya kami ucapkan kepada Lembaga Penelitian Pengabdian Masyarakat (LPPM) Institut Teknologi PLN yang telah membiayai Kegiatan Pengabdian Pada Masyarakat Tahun Anggaran 2019 ini.

\section{DAFTAR PUSTAKA}

[1] Chang, K.-E., Chang, C.-T., Hou, H.-T., Sung, Y.-T., Chao, H.-L., \& Lee, C.-M., 2014, Development and behavioral pattern analysis of a mobile guide system with augmented reality for painting appreciation instruction in an art museum. Computers \& Education, 71, 185-197.

[2] Di Serio, Á., Ibáñez, M. B., \& Kloos, C. D., 2013, Impact of an augmented reality system on students' motivation for a visual art course. Computers \& Education, 68, 586-596. doi:10.1016/j.compedu.2012.03.002.

[3] I Made Sumartha Yasya, 2014, Pengembangan Alat Ukur Sikap Nasionalisme Pada Siswa RSBI SMA Negeri 1 Gianyar Tahun Pelajaran 2011-2012. 
[4] Kuldep Kumar, Manas Manbhav, Smith Dhavale, 2015, Living With Technology Through Augmented Reality. IJETEE-ISSN:2320-9569 Vol.11.

[5] Muhammad Hadi Noor Seto, Tri Listyorini, Arief Sutanto, 2015, Pengenalan Pahlawan Indonesia Berbasis Augmented Reality dengan Marker Uang Indonesia. Jurusan Teknik Informatika Fakultas Teknik Universitas Maria Kudus. Prosiding SNATIF ISBN:978-6021180-21-1.

[6] Muhammad Rifa'i, Tri Listyorini, Anastasya Latubessy, 2014, Penerapan Teknologi Augmented Reality pada Aplikasi Katalog Rumah Berbasis Android. Jurusan Teknik Informatika Fakultas Teknik Universitas Maria Kudus.

[7] Yessy Asri, 2015, Rancang Bangun Aplikasi Berbasis Flash Flip Book Untuk Mengukur Tingkat Nasionalisme Murid-murid SD. Jurusan Teknik Informatika STT PLN.

[8] Arikunto, Suharsimi, 2008, Dasar-Dasar Evaluasi Pendidikan. Jakarta:Bumi Aksara. Latipun (2008), Psikologi Eksperimen, Malang: Universitas Muhammadiyah Malang Press.

[9] Nashar, Drs, 2004, Peranan Motivasi dan Kemampuan Awal dalam Kegiatan Pembelajaran. Jakarta: Delia Press.

[10] Panggabean, Luhut, 1996, Penelitian Pendidikan.Depdikbud: Bandung.

[11] Sadiman, Arief, 2003, Media Pendidikan Pengertian, Pengembangan dan Pemanfaatannya. Jakarta:PT RajaGrafindo Persada.

[12] Sunarso, Drs, MSi, 2019, Pelajaran PKn 4, Yudhistira, Jakarta

[13] Susilana, R dan Riyana, C., 2008, Media Pembelajaran: Hakikat, Pengembangan, Pemanfaatan, dan Penilaian. Bandung: CV. Wacana Prima.

[14] Ruseffendi, 1992, Statistika Dasar untuk Penelitian Pendidikan. Depdikbud: Bandung.

[15] Tim Sosialisasi Empat Pilar, 2012, Empat Pilar Kehidupan Berbangsa dan Bernegara, Jakarta.

[16] Kaelan MS, 2010, Pendidikan Pancasila, Paradigma: Jakarta. 